\title{
UNA HABITACIÓN PROPIA PARA LAS MUJERES EN LAS ARTES VISUALES
}

A ROOM OF ONE'S ONE TO WOMEN IN VISUAL ART

\author{
Vanesa Cejudo \\ Investigadora y miembro de la Junta Directiva de MAV
}

\section{RESUMEN}

La construcción de significados modela la narración de nuestro ecosistema relacional. Es fundamental, por lo tanto, poder identificar los dispositivos y las estructuras hegemónicas que hacen perpetuar, década tras década, un relato androcéntrico que supone la invisibilización de las creaciones que generan la otra mitad de la humanidad: la de la mujer. A través de diferentes estructuras feministas dentro de las artes visuales, se pretende mostrar otras formas de hacer dentro del sector, con el eje central de la asociación MAV (Mujeres en las Artes Visuales), siguiendo con otros ejemplos internacionales como la galería-cooperativa A.I.R. (Artist In Residence) y el movimiento Guerrilla Girls. De esta manera podremos imaginar desde un posicionamiento feminista: la creación visual contemporánea, la forma de gestionar este patrimonio visual, y su relación con el mercado. Unas formas de hacer en el arte que difieren a las maneras hegemónicas patriarcales acostumbradas. Hablamos de formas de cooperación, de visualización en red y de optimización de recursos.

Palabras Clave: Mujeres en las artes visuales, igualdad en sistema del arte, feminismo, asociacionismo, cooperativismo.

\section{ABSTRACT}

Our relationships are modelled through the construction of meanings. For this reason, it is important to know which are the hegemonic structures that create the values and the meaning of our rules in our society. So far it has been in the hands of one of the halves of humanity: the masculine. Through different feminist groups in the visual arts sector: MAV (Women in Visual Arts), the cooperative-gallery: A.I.R. (Artist In Residence) and the Guerrilla Girls movement, we can know a different way of dealing with visual art, to create out of the patriarchy thoughts. A form of management and creation based on feminist positions: cooperation, optimization of resources and networking.

Keywords: Women in Visual Arts, Feminism, Gender Equality, Associations, Cooperative Movement. 


\section{SUMARIO}

1.- Una reflexión en torno a la igualdad en las artes visuales: la construcción de una realidad incompleta.

2.- Origen de la asociación Mujeres en las Artes Visuales, MAV. 3.- Promoviendo un arte visual feminista.

3.1.- La visibilización, como presencia. 3.2.- La denuncia, como voz. 3.3.- La reflexión, como actitud.

4.- Conclusiones. 5.- Referencias bibliográficas. 5.1.- Webgrafía.

\section{Una reflexión en torno a la igualdad en las artes visuales: la construcción de una realidad incompleta}

Intentar enmarcar la lucha feminista en las artes visuales es una tarea difícil e inagotable por la cantidad de aristas que la propia realidad presenta; por ese motivo la cuestión que se quiere abordar es aquella que se presenta como esencial y estructural, como razón que perpetúa una desigualdad inherente en la forma de convivir en sociedad, latente en la cultura, y consecuentemente en las artes.

La reflexión se centra en identificar las estructuras hegemónicas y los dispositivos que la mantienen, década tras década, como único relato androcéntrico. Un sistema que construye las bases para interpretar lo real y vertebrar la verdad, a partir de un orden y una normalidad establecida por hombres blancos, de economía saneada y de sociedades democráticas:

El hecho es que la igualdad sólo afecta a quienes disfrutan de una posición de privilegio: hombres blancos, de economía saneada, y pertenecientes a ese país donde se formulan las leyes de igualdad (Hernando: 2015: 15).

Estos relatos blancos han sido inoculados en la sociedad gracias a una estructura de poder que ha hecho posible que este perfil narrador de la normalidad y de las verdades, ocupe lugares estratégicos donde su voz y opinión tiene una gran repercusión; generando un gran impacto social, en el que además no tienen cabida, el cuestionamiento y la reflexión crítica, de una oposición.

La perpetuidad de estos sistemas hegemónicos, afloran como cuasi certezas dado que las propias estructuras de poder tienen sus mecanismos para no identificarlos como imposición o violencia simbólica, como alude Bourdieu. La normalidad social tiene sus propias dinámicas, o dispositivos, como los llama Foucault, para poder impactar en la sociedad como un relato verdadero y prácticamente único. 
Todo poder de violencia simbólica, o sea, todo poder que logra imponer significados e imponerlas como legítimas disimulando las relaciones de fuerza en que se funda su propia fuerza, añade su fuerza propia, es decir, propiamente simbólica, a esas relaciones de fuerza (Bourdieu, 1977: 44).

Estos dispositivos evolucionan en forma de red, posibilitando que los constructos sociales sean percibidos con absoluta normalidad. Así, nuestro entorno es entendido a través de un holgado tamiz donde las personas nos sentimos dueñas de nuestros comportamientos, porque el poder, o la violencia simbólica, a la que se refiere Bourdieu, ha sido interiorizada dentro de su propio proceso de asimilación.

$Y$ es que, volviendo a Almudena Hernando, poder pensar de manera autónoma, significa entender cualquier tipo de dominación que ha sido normalizada en nuestro ecosistema, identificarla y actuar consecuentemente:

Ser feminista no significa sólo luchar de forma activa por la igualdad, es colocarse como sujetos en una posición autónoma y ajena a cualquier tipo de dominación, y de autoritarismo, y por lo tanto difiere de esa manera, sutil y subordinada en la que se está enseñando a entender el mundo a las mujeres (Hernando: 2015: 15).

Ahora bien, si aumentamos el macro, y apuntamos al sector de las artes -y en concreto a las artes visuales- cobra aún más importancia la situación de desequilibrio, por el doble sentido de esta desigualdad.

Las creaciones de las mujeres del sector conviven con las creaciones de los hombres, haciéndose visibles con matices diferentes. La construcción de relatos visuales bajo autorías femeninas se ve reducida a anécdotas, siendo muchas interpretadas en torno a cuestiones sentimentales o emocionales; en donde se da a conocer la narración de la vida personal, más que el de las propias creaciones (véanse los casos de las mujeres artistas que nombran las personas de la calle': Frida Kahlo, Ana Mendieta, Marina Abramovic, etc.) Si indagamos sobre lo que conocen de ellas la mayoría de la población nos contaría la historia-drama personal de las artistas, más que el impacto de sus obras.

La segunda diferencia es la desigualdad hacia dentro, simbólica e invisible, donde las mujeres, apoyadas en roles de cuidados poco reconocidos en sociedad, e invisibilizados como valor (Durán, 2012), crean representando universos que también son juzgados como

\footnotetext{
1 Ejercicio que realizó MAV para la Bienal Mirada de Mujeres, en el que se realizó un video promocional basado en interrogar a personas de la calle con varias preguntas, entre ellas: ¿̇qué mujer artista conoces? $\dot{\partial}^{T}$ Tiene sentido en la actualidad, una bienal de mujeres? https://vimeo.com/266510388
} 
menores (escenas domésticas, partos, crianzas, etc.), «inconscientemente» son devaluadas dentro del imaginario social, y consecuentemente, en el mercado del arte.

Eso sin nombrar la que quizás sea la lucha más encarnizada del feminismo, en la que las mujeres se ven obligadas durante siglos, a elegir entre su desarrollo profesional, o su dedicación familiar. Así se rescatan las ya conocidas palabras de Virginia Woolf, de hace casi un siglo atrás:

La libertad intelectual depende de cosas materiales. La poesía depende de la libertad intelectual. Y las mujeres siempre han sido pobres, no sólo durante doscientos años, sino desde el principio de los tiempos. Las mujeres han gozado de menos libertad intelectual que los hijos de los esclavos atenienses. Las mujeres no han tenido, pues, la menor oportunidad de escribir poesía. Por eso he insistido tanto sobre el dinero y sobre el tener una habitación propia (Woolf: 1929: 77).

Y es que las consecuencias más impactantes de esta múltiple discriminación, se refleja en cómo más de la mitad de la humanidad no tiene la misma oportunidad para construir relatos, ni visiones, ni versiones de la realidad en la que vivimos. «A través de las narraciones audiovisuales, el cincuenta por ciento de la humanidad, la masculina, sigue construyendo la mirada y el lenguaje de todos». (Aguilar: 1998: 29)

En todo este contexto nace Mujeres en las Artes Visuales -en adelante MAV-, con la intención de pensar, actuar y denunciar, aquello que atenta a la igualdad entre hombres y mujeres, en el sector profesional de las artes visuales en España.

\section{Origen de la asociación: Mujeres en las Artes Visuales, MAV}

MAV nace tras las mesas de debate que organiza el Ministerio de Cultura en marzo de 2009. Este encuentro propicia que diferentes profesionales del sector de las artes visuales creen un grupo de trabajo de mujeres con diversos perfiles profesionales: Margarita Aizpuru, Oliva Arauna, Magda Belloti, galeristas; Teresa Moro, Marina Núñez, artistas; e Isabel Tejeda, Rocío de la Villa, Patricia Mayayo, investigadoras y comisarias, Tras un intenso debate e intercambio de experiencias, se hace visible la necesidad de defender la igualdad dentro del sector de las artes visuales.

La asociación fue fundada por la profesora y crítica de arte Rocío de la Villa el 9 de mayo de 2009 en una reunión celebrada en La Casa Encendida de Madrid con la participación de artistas, comisarias, directoras de centros, críticas, investigadoras, galeristas y gestoras. La finalidad fue unirse legalmente como una asociación nacional con la premisa 
de combatir la desigualdad de las mujeres en el arte contemporáneo. Se ampara en el marco del cumplimiento de la Ley para la igualdad efectiva de mujeres y hombres del artículo 14 de la Constitución Española del año 2007. Y la aplicación práctica de esta filosofía en las instituciones públicas con la aún más reciente Ley Orgánica 3/2007, de 22 de marzo, que en su Artículo 26, dice textualmente:

La igualdad en el ámbito de la creación y producción artística e intelectual. 1. Las autoridades públicas, en el ámbito de sus competencias, velarán por hacer efectivo el principio de igualdad de trato y de oportunidades entre mujeres y hombres en todo lo concerniente a la creación y producción artística e intelectual y a la difusión de la misma. 2. Los distintos organismos, agencias, entes y demás estructuras de las administraciones públicas que de modo directo o indirecto configuren el sistema de gestión cultural, desarrollarán las siguientes actuaciones: a) Adoptar iniciativas destinadas a favorecer la promoción específica de las mujeres en la cultura y a combatir su discriminación estructural y/o difusa. b) Políticas activas de ayuda a la creación y producción artística e intelectual de autoría femenina, traducidas en incentivos de naturaleza económica, con el objeto de crear las condiciones para que se produzca una efectiva igualdad de oportunidades. c) Promover la presencia equilibrada de mujeres y hombres en la oferta artística y cultural pública. d) Que se respete y se garantice la representación equilibrada en los distintos órganos consultivos, científicos y de decisión existentes en el organigrama artístico y cultural. e) Adoptar medidas de acción positiva a la creación y producción artística e intelectual de las mujeres, propiciando el intercambio cultural, intelectual y artístico, tanto nacional como internacional, y la suscripción de convenios con los organismos competentes. f) En general y al amparo del artículo 11 de la presente Ley, todas las acciones positivas necesarias para corregir las situaciones de desigualdad en la producción y creación intelectual artística y cultural de las mujeres (3/2007: Ley Orgánica Art. 26).

A partir de ese momento, comienzan a generarse diversas líneas de acción para la consecución de estos fines, que se recogen en los estatutos de la asociación:

1.--Promover los objetivos de igualdad real y efectiva de mujeres y hombres en todos los ámbitos, tanto públicos como privados, relacionados con las artes visuales. 2.- Impulsar para ello la aplicación del artículo 26 de la Ley de lgualdad, que propone actuaciones que promuevan a las mujeres y combatan su discriminación en el ámbito de la creación y producción artística e intelectual. 3.- Constituirse en interlocutor de las Administraciones Públicas en el Estado Español, en todos cuantos asuntos afecten al desarrollo de la actividad de las mujeres en las artes visuales. 4.- Convertirse en foro de reflexión y pensamiento en el ámbito del feminismo y las artes visuales. 5.- Configurarse como red de vertebración y difusión de las actividades que, bajo una perspectiva de género, se lleven a cabo en el ámbito de las artes visuales, para darles mayor visibilidad y efectividad. 6.- Servir como plataforma de apoyo mutuo, colaboración y comunicación entre las asociadas de los distintos sectores integrados en la Asociación. 7.Establecer conexiones y colaboraciones con instituciones, asociaciones o colectivos sociales 
que compartan los fines de la Asociación, con el fin de optimizar las estrategias comunes. 8.- Defender los derechos, aspiraciones y objetivos comunes de sus asociadas, en todos los ámbitos de su competencia. 9.- Promover, apoyar y difundir iniciativas que impulsen los fines de la Asociación (MAV: 2009).

Actualmente la asociación está compuesta por cerca de 500 socias de perfiles profesionales muy diferentes: artistas, investigadoras, críticas, gestoras, comisarias y mediadoras culturales, y cuatro claras líneas de actuación en el ejercicio de la defensa de la práctica feminista en las artes visuales: la Bienal Mirada de Mujeres, El Foro, Los premios MAV y el Observatorio por la lgualdad. Por otro lado, en el año 2012 se fundó la revista online M-Arte y Cultura Visual, con el objetivo de abordar el arte y la cultura visual desde una perspectiva de género. Su fundadora, fue Rocío de la Villa. En el Foro 2017, se publicó el primer número impreso tras cinco años de publicaciones online.

\section{Promoviendo un arte visual feminista}

Desde su constitución como asociación cultural sin ánimo de lucro, MAV viene desarrollando diferentes acciones, que podríamos resumir en grandes ejes de acción: 3.1. La visibilización, como presencia; 3.2. La denuncia, como voz; 3.3. La reflexión, como actitud.

\subsection{La visibilización, como presencia}

En el año 1970, cuando en la opinión pública aún no existían movimientos feministas, aflora en el museo Whitney de Nueva York una protesta sobre la escasa participación femenina: Tan sólo un cinco por ciento de las obras expuestas eran de mujeres. Este hecho será el detonante para que Lucy Lippard, crítica de arte, junto con las artistas, Dotty Attie y Mary Grigoriadis, empiecen a actuar decididamente ante tal desigualdad. Así comienza en 1974, A.I.R. (Artist In Residence), una galería-cooperativa de profesionales del sector, constituida unicamente por mujeres. Bajo una exhaustiva selección de artistas, de las cuales, algunas de ellas, se niegan a pertenecer por ser una galería formada solamente por mujeres. Posiblemente se cree, temerosas a ser juzgadas como mujeres y no como artistas.

Sin embargo, la organización sabía a lo que se enfrentaba, y es que no era simplemente un reto para el mercado y el sector profesional del arte; era, ante todo, un desafío frente a una sociedad anclada en códigos machistas y androcéntricos. Por esta razón pusieron su mayor ímpetu en generar una estructura que respondiera tanto en su funcionamiento interno, como en su expresión hacia el exterior, de una manera completamente diferente, autónoma y

Dossiers Feministes, 23, 2018, 23-41 - ISSN: $1139-1219$ - DOI: http://dx.doi.org/10.6035/Dossiers.2018.23.2 
auténtica en su gestión. A.I.R. puso su énfasis en realizar exhibiciones de la máxima calidad, donde no cabria la duda sobre la índole del arte que se exponía. La peculiaridad de A.I.R. no era únicamente que se mostraba un buen arte realizado por mujeres; el máximo impacto fue su revolucionaria forma de exhibición de obra, basándose en estructuras democráticas, donde cada una de las miembros participa activamente en la toma de decisiones. Además, la propiedad de la cooperativa estaba en manos de todas las socias, teniendo repartida la dirección de la galería en cada una de ellas en partes iguales.

Por otro lado, ingenian su propio protocolo en la apertura a nuevas profesionales que quisieran adherirse a A.I.R, donde era, y es necesario pasar por una rigurosa evaluación a pares, además de someterse a debates y discusiones de todas las miembros de la galeríacooperativa.

También se innova en la manera en la que se delegan ciertas responsabilidades; las mujeres que pretendan exhibir obra en la galería, deben tener que realizar, además, el trabajo curatorial, lo que permite cierta experimentación y riesgos que no siempre son posibles en el ámbito puramente comercial. Tampoco abandonaron la cuestión de visibilidad en el exterior, entre sus grandes hazañas estuvo y está, la de conseguir tejer una red de intercambios internacionales que les otorgó un reconocimiento fuera del propio New York.

La cooperativa fue, y es, un hito social, no sólo porque exhibe un buen arte de mujeres, sino porque significó una nueva forma de mostrar arte, una nueva fórmula de trabajar con el arte y una nueva manera de dialogar con el poder, la visibilidad y las decisiones.

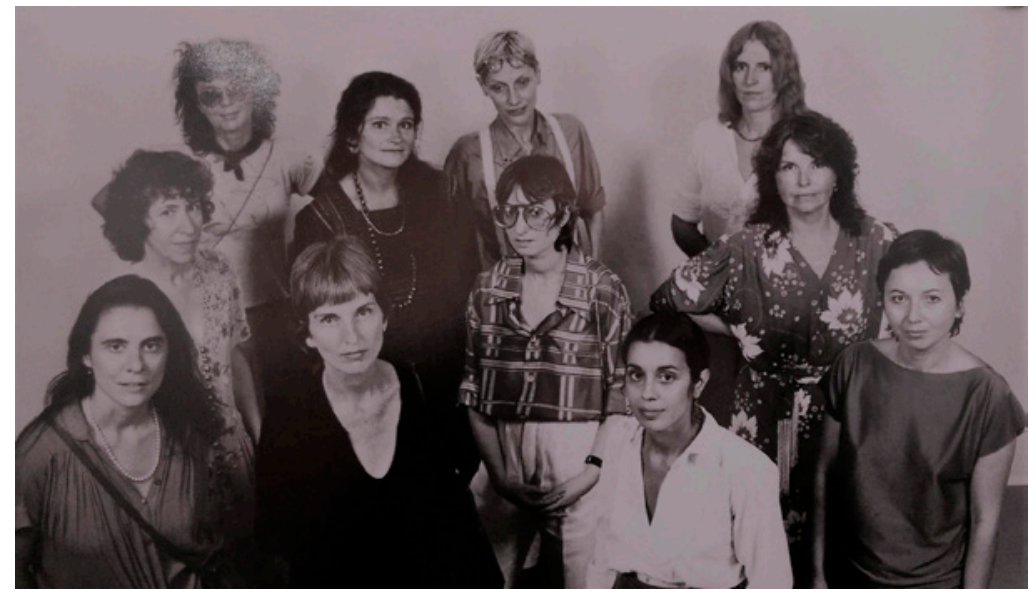

Fig. 1. Fotografía de las artistas de la cooperativa A.I.R, Exhibida en Freeze 2017. Londres. 
$Y$ es que uno de los ejes fundamentales para poder luchar por la igualdad en el sector de las artes, es mostrar el trabajo realizado por las creadoras, alimentando los relatos, y generando imaginarios que nos permitan construir diferentes maneras de pensar y de estar en sociedad. MAV, consciente de lo importante que es la visibilidad de las artistas, crea dentro de sus posibilidades, pero con todos sus recursos, un formato de exhibición de obra de mujeres artistas en donde aglutina esfuerzos creativos, institucionales, profesionales y económicos, para así tejer una red de visibilidad: la Bienal Mirada de Mujeres.

La bienal aglutina, durante todo un año, más de cien actividades de las artes visuales, y promueve tanto la diversidad de género, como la diversidad cultural. El formato de bienal creado por MAV, se estructura en base a dos líneas: una, por invitación; llamando a formar parte de ella a instituciones o iniciativas particulares que tengan planteamientos $y / 0$ contenidos feministas acordes con la filosofía de la bienal. O dos, por selección; convocando a todas las iniciativas particulares con más de un $60 \%$ de mujeres en sus equipos, a presentar proyectos de creación artística para que sean producidos y promocionados por la bienal.

Se pretende de esta manera, que la Bienal Miradas de Mujeres sea un lugar de referencia para el encuentro de la creación femenina a nivel local, nacional e internacional.

Este año fueron seleccionados cinco proyectos por un comité externo formado por la directora de la Casa Encendida Tania Pardo, El director del Centro de Arte 2 de Mayo, Manuel Segade, dos miembros de la junta Joanna Baygual, artista y María Jesús Abad, profesora y comisaria, y dos socias de MAV elegidas aleatoriamente: Erika Bornay, escritora e investigadora, y Ana Revilla, gestora y comisaria.

Los cinco proyectos seleccionados son todo un universo creativo en donde se puede entender la riqueza creativa. El proyecto de Gloria Oyarzabal, «Woman go no'gree»:

... explora las consecuencias del eurocentrismo y la racialización del conocimiento: Europa se representa como la fuente del conocimiento y los europeos, por lo tanto, como pensadores. Además, el privilegio masculino como parte esencial del ethos europeo está implícito en la cultura de la modernidad. ¿े Qué pasa si los modelos de la modernidad nos llevan a una nueva visión del «otro»? (Oyarzabal: 2018)². 


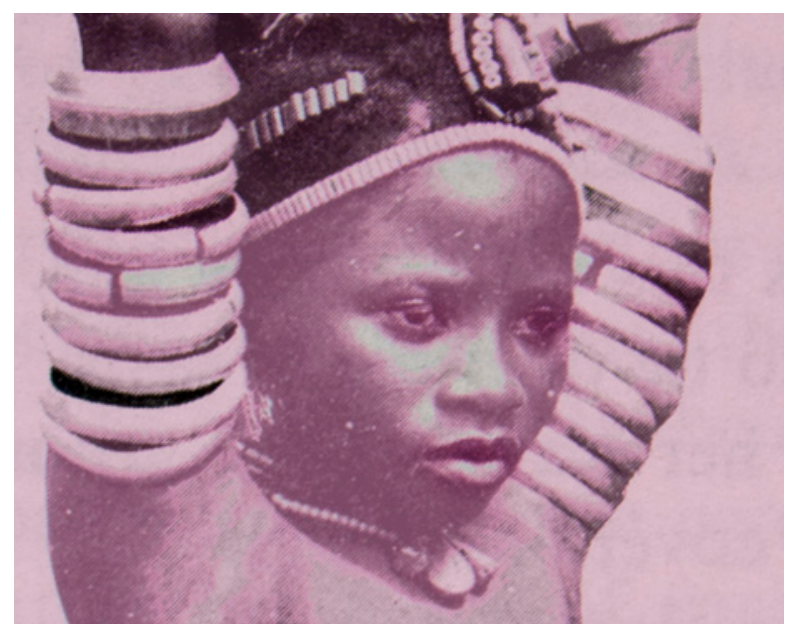

Fig. 2. Gloria Oyarzabal, Woman go no'gree.

«The Boogie - Woogie Ghost», un proyecto de María Jerez y Silvia Zayas:

... investiga las posibilidades del dispositivo propuesto y la agencia de los objetos, así como las relaciones no solo espaciales sino temporales y coreográficas de una película de unos $20^{\prime}$ $30^{\prime}$ de duración en un espacio cotidiano, como un salón. La idea de usar un espacio cotidiano, una casa, quiere incidir en la utilización de los objetos y mobiliario conocidos con la intención de desestabilizar sus contornos fijos y sus usos predeterminados que, en combinación con otros materiales más abstractos, proponen un espacio de indeterminación e incertidumbre (Jerez y Zayas: 2018).

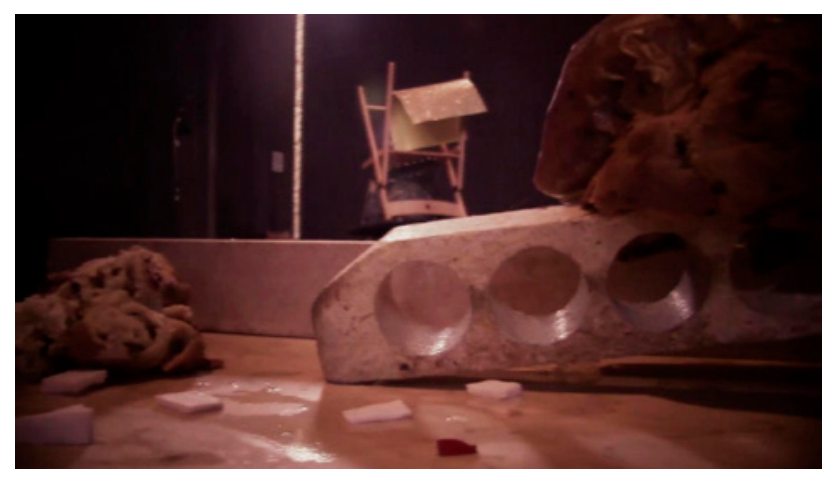

Fig. 3. María Jerez y Silvia Zayas, Fotogramas The Boogie - Woogie Ghost. 
«Ecologismos femeninos» es un proyecto de Verónica Álvarez, que:

... propone una serie de talleres para transmitir el conocimiento feminista y ecológico a través de la acción y experimentación artística, así como las diferentes teorías y cuestiones medioambientales-sociales y de género, combinando la práctica artística y performática de artistas e investigadoras que trabajan de manera activa sobre la concienciación medioambiental a través de sus obras y su relación con el medio rural (Álvarez: 2018.

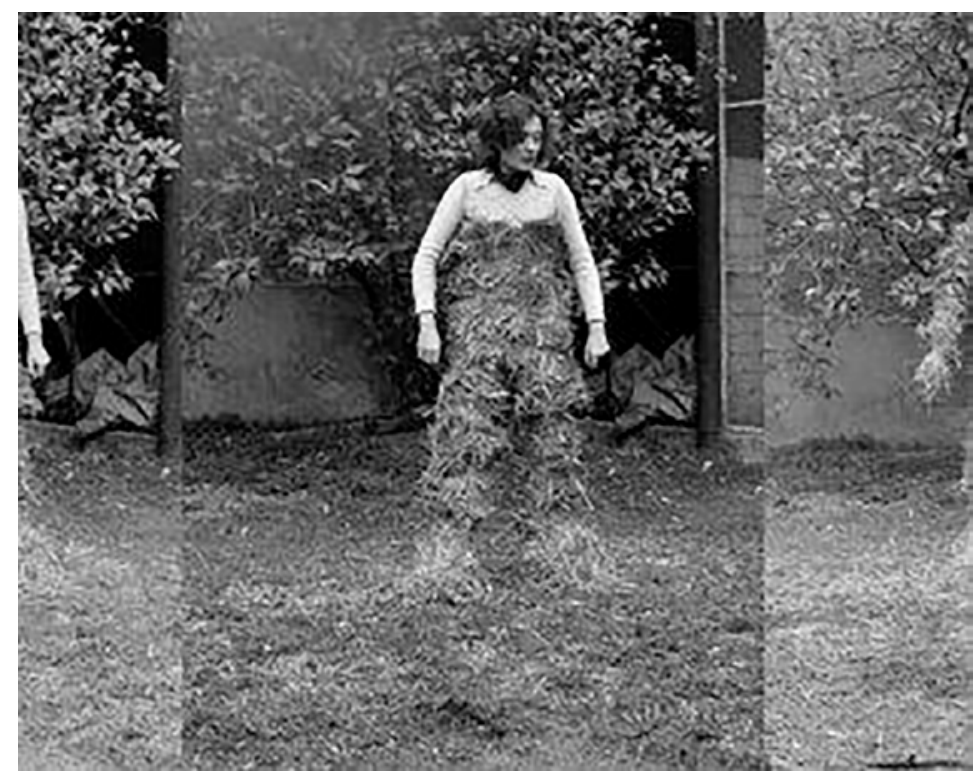

Fig. 4. Verónica Álvarez, Ecologismos femeninos.

«La Gran Vaca Mecánica» de Lina Bo Bardi, una colaboración de Mara Sánchez Llorens, María Toledo y Manuel Fontán del Junco:

... es una propuesta para la reconstrucción, acción urbana participativa y posterior dinamización pedagógica de la obra diseñada por la creadora ítalo-brasileña en 1988 que formará parte del programa de actividades que se desarrollarán en el marco de la exposición Lina Bo Bardi: tupí or not tupí. Brasil, 1946-1992 que la Fundación Juan March (Sánchez, Toledo y Fontán del Junco: 2018). 


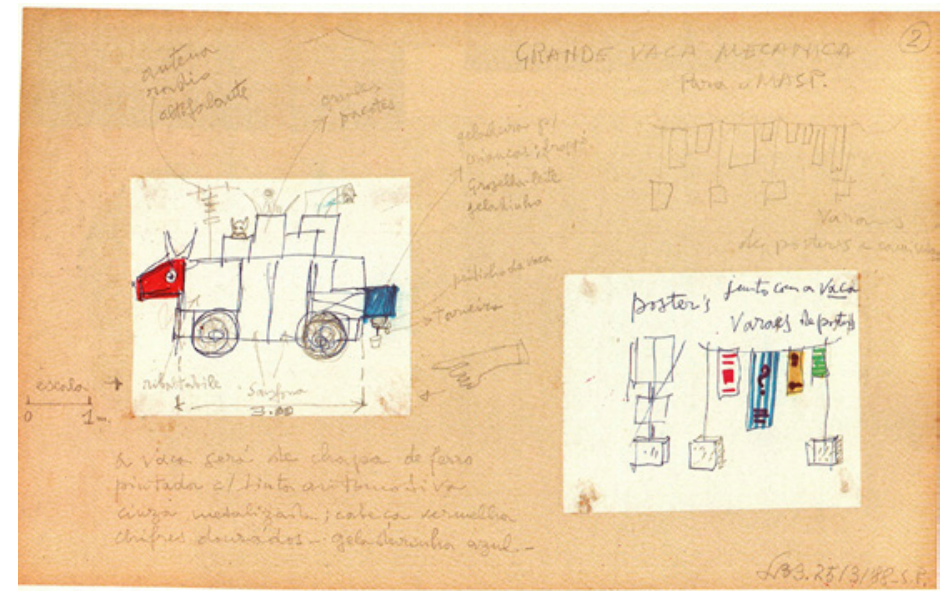

Fig. 5. Lina Bo Bardi, La Gran Vaca Mecánica.

El último de los proyectos seleccionados es «Argamasa», plataforma sonora formada por Mariana Heredia, Carmen José y Marina Rengel Lucena:

...los contenidos proceden de una serie de sesiones y acciones que son resultado de una colección de fragmentos asociados libremente, formados por lecturas, ambientes sonoros, charlas, playlists, etc; creada en torno a asociaciones, personas, iniciativas y textos que cuestionan los discursos heteropatriarcales (Heredia, José y Lucena: 2018).

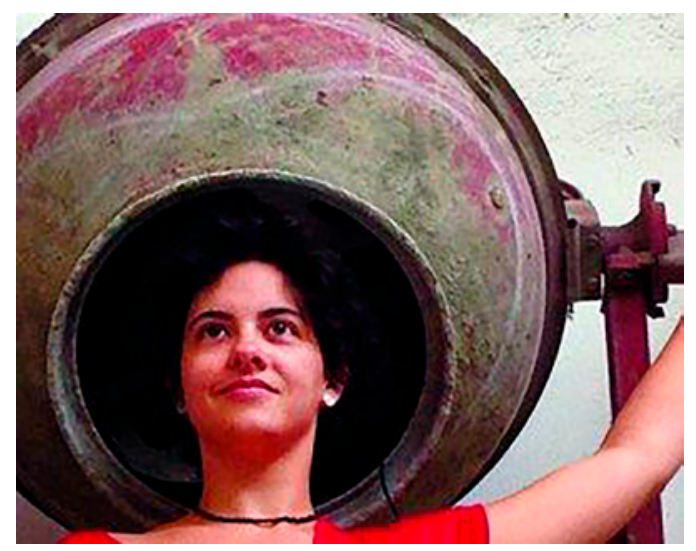

Fig. 6. Mariana Heredia, Carmen José y Marina Rengel Lucena, Colectivo Argamasa. 
La visibilidad es uno de los grandes retos que MAV persigue, por democracia y porque la sociedad tiene que enriquecerse con un relato completo, en donde las mujeres crean, dicen y piensan, y construyen futuribles dignos de ser vistos, oídos y pensados.

\subsection{La denuncia, como voz}

En 1984, una exhibición en el MoMA de Nueva York muestra una representación de pintura y escultura contemporánea en la que se podía ver obra de 165 artistas de 17 países, sin embargo, solamente 13 de esos artistas, eran mujeres. Las trece artistas propuestas, eran blancas occidentales.

La respuesta no se dejó esperar, siete mujeres anónimas comenzaron a denunciar esta desigualdad con máscaras de gorilas. Nace, Guerrilla Girls.

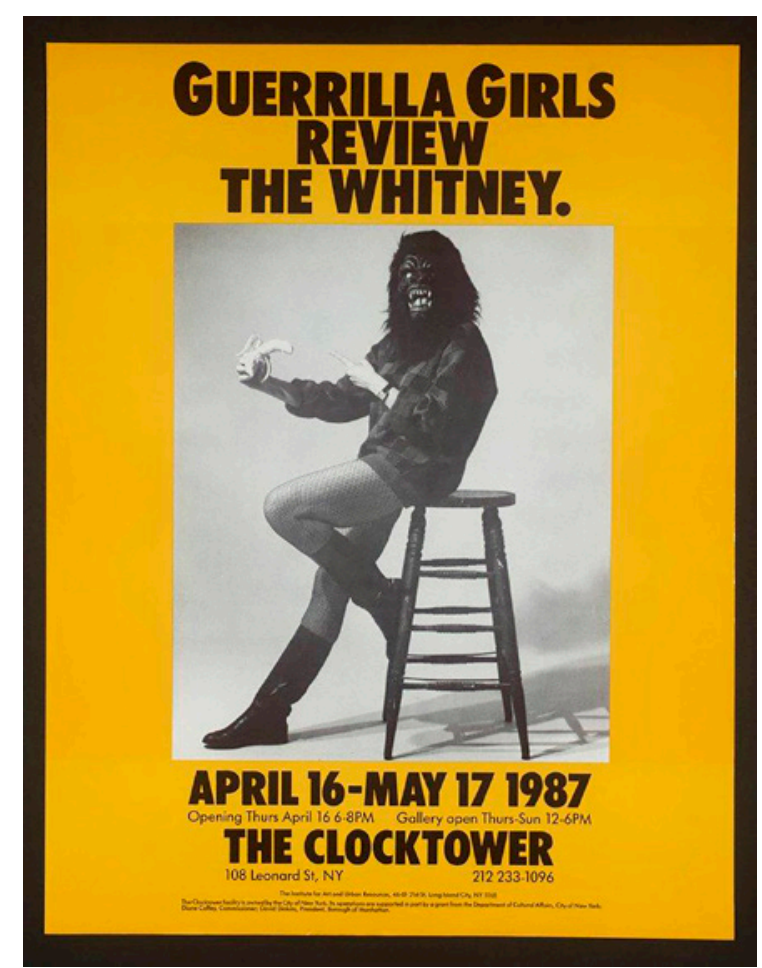

Fig. 7. Guerrilla Girls, Guerrilla Girls Review The Whitney, 1987. 
Desplazar el asunto de la desigualdad del territorio de la opinión necesita de datos contundentes y contrastables, contextos de muestra de esos datos, y una cierta escenografía que favorezca que esa información pueda ser difundida entre un amplio sector profesional y social. Las Guerrilla Girls, han sido y son un movimiento mítico, por la manera tan particular de presentar estos datos de la desigualdad, y por su determinante código panfletario, en donde llaman la atención no sólo en el mundo del arte, sino en un entorno social y económico que alimenta inevitablemente ese desequilibrio.

La denuncia es la voz articulada en deseos de cambio, es la manera de mostrar que la desigualdad es un hecho demostrable y palpable, y en MAV se denuncian los incumplimientos de la ley de igualdad en las artes visuales, desde muy diferentes frentes:

1- Llevando los casos graves hasta el defensor del pueblo.

2- Creando cartas denuncia a las instituciones que incumplen la ley de igualdad.

3- Uniéndonos en red a otras asociaciones afines en el sector de la cultura, para poder generar movimientos más contundentes, y sostenibles en el tiempo para permitir, de esa manera, tener interlocución con los organismos institucionales, que crean o velan por el cumplimiento de las leyes.

4- Recogiendo periódicamente los datos de la desigualdad, centrando estos informes en las ferias de arte contemporáneo, las adquisiciones de los centros de arte nacionales, las exhibiciones de los centros y museos, y actualmente, recaudando el dato de las mujeres que terminan sus estudios en el sector de las artes visuales.

El informe más reciente fue el que presentó MAV tras las ferias de arte contemporáneo celebradas en Madrid 2018. Las cifras recogidas son bastante contundentes. Además estas cifras han sido recabadas durante casi una década, permitiéndonos realizar una lectura longitudinal del fenómeno de la desigualdad en las ferias de arte contemporáneo.

El primero de los síntomas, el más alentador, es que las ferias nuevas, las más innovadoras, como Just MAD e Hybrid, muestran otro espíritu y otras prácticas que nos dan esperanza para pensar que puede haber un cambio futuro.

Hybrid, en su segunda edición, presenta estos datos: Galeristas: Hombres 30\%, Mujeres $46 \%$, Mixto $24 \%$, Artistas: Hombres $40 \%$, Mujeres $53 \%$, Mixto y no especificado $7 \%$, en cuanto al Género del comité ejecutivo está compuesto por un $100 \%$ mujeres.

La feria JUSTMAD9, en su novena edición, pasa de un 35\% de representación de artistas mujeres a un $49,6 \%$ en tan sólo un año; y su comité ejecutivo está formado en $66,7 \%$ de mujeres frente a un $33,3 \%$ de hombres.

La segunda tendencia muestra un enquistamiento en la feria internacional ARCO, en una desigualdad estructural que se prolongará otra década más, si no hay voluntad 
de cambiar la composición de los comités ejecutivos. Tomando parte de estos datos para analizar la situación, tenemos que la cifra de nacionalidad y género del artista, tiene una representación de 84 artistas mujeres españolas de un total de 1323 artistas individuales. Esto se traduce en que de todos los artistas presentados en la feria, un $6 \%$ son mujeres artistas españolas.

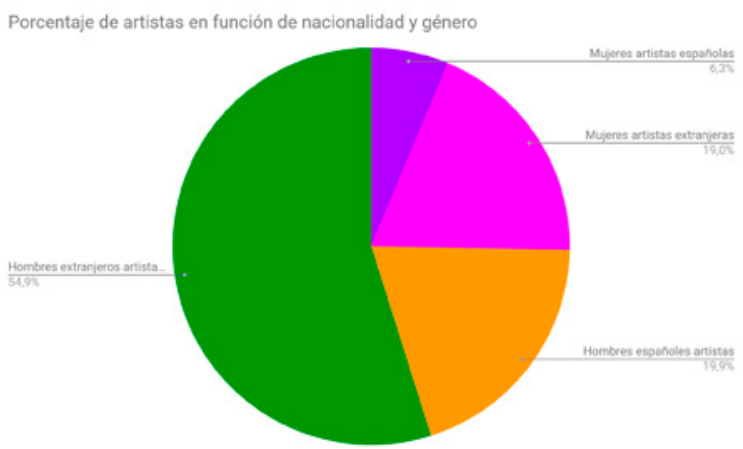

Gráfico 1. Presencia de artistas mujeres con nacionalidad española en ARCO 2018.

¿Y, qué hay de las galerías de ARCO? ¿Cuál es la lectura de género que debemos hacer?

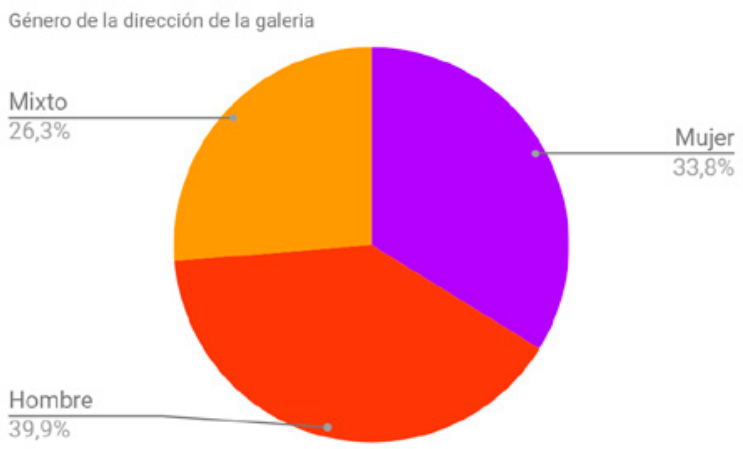

Gráfico 2. Proporción de género en la dirección de las galerías en ARCO 2018.

Este dato muestra cierta paridad en la dirección de galerías de arte lideradas por mujeres y hombres, y ciertamente hay un gran número de galerías llevadas por equipos mixtos. Pero no se puede leer sin este otro ¿qué artistas venden nuestras galeristas? Las 
galerías dirigidas por hombres exponen: un $82 \%$ de hombres, $17,5 \%$ de mujeres, y un $0,5 \%$ de colectivos mixtos. Las galerías dirigidas por mujeres exponen: un $65 \%$ de artistas hombres, un $32 \%$ de artistas mujeres y un $3 \%$ de colectivos de artistas. Las galerías de artistas con dirección mixta: un $29,3 \%$ de mujeres artistas, un $70,5 \%$ de hombres, y un $0,3 \%$ de colectivos mixtos (MAV: 2018).

Esta cifra habría que interpretarla en clave mercantil, e intentar investigar qué mueve a estas mujeres (y hombres) galeristas, a vender en una proporción tan alta la obra de artistas hombres.

Entendemos que una galerista es ante todo una mujer de negocios, no es una institución pública, ni es un organismo independiente del mercado, se rige por lógicas mercantiles y estas lógicas de mercado están completamente contaminadas por un sistema patriarcal de incentivos, de apoyos y de visibilidad al artista varón. La causa puede ser porque las obras más demandadas son las que son premiadas, las más expuestas y las más visibles, y por lo tanto estas, son las que tienen más posibilidad de venta.

Y ahora viene la clave de la cuestión ¿̇quién elige a los premiados? , ¿quién decide qué exponer?, ¿̇quién habla, escribe o difunde al artista? Evidentemente, en una gran proporción son hombres. Los hombres ocupan los territorios de poder, los espacios de decisión y los lugares de altavoz.

Esta afirmación lo corroboran los datos, que muestran que casi un $80 \%$ de las decisiones que se toman en una feria internacional como ARCO, está en manos de hombres. Las mujeres lideran otros puestos de gestión, de asistentes, y de cuerpos técnicos, pero los puestos de mando siguen estando en voz y manos de los hombres.

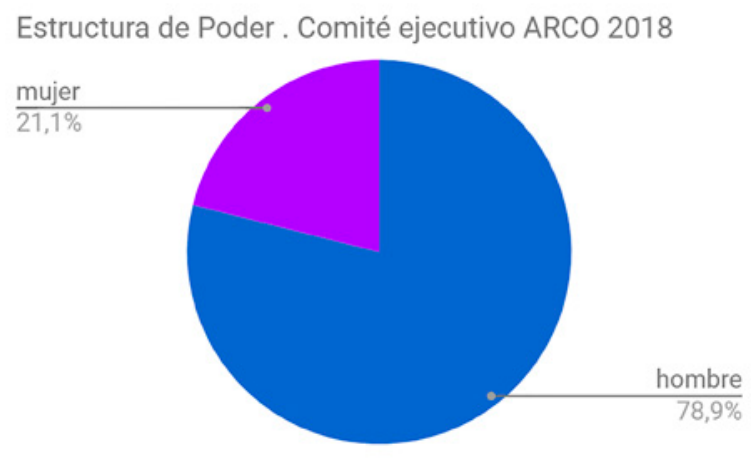

Gráfico 3. Comité ejecutivo de ARCO 2018, en clave de género. 
Y analizando la asignación de los premios del año 2017. Se muestra que los hombres artistas han sido premiados en $71,4 \%$ de las ocasiones, y tan sólo un $28,6 \%$ han sido mujeres artistas.

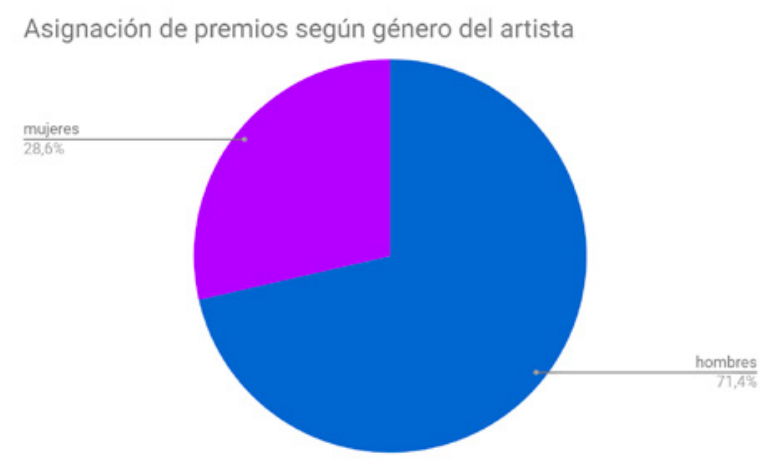

Gráfico 4. Asignación de premios, según género del artista ARCO 2017.

En definitiva, se podría decir que la desigualdad está enquistada en las estructuras de poder, y reflejada en las lógicas de la normalidad. En donde no sólo son ocupadas en un porcentaje desproporcionado por hombres, sino que además lo hacen hombres no feministas.

\subsection{La reflexión, como actitud}

Una parte vital de la asociación es la que permite pensar sobre los ejes de acción MAV. El Foro, es el refugio donde se aglutinan las dudas y las directrices futuras resueltas de la manera más democrática dentro de las sesiones abiertas, que se celebran.

En el último de los Foros, celebrado en noviembre del 2017, se puso en evidencia en la mesa moderada por Fátima Anllo: «Las mujeres y el poder en el sistema del arte», y presentada por Almudena Hernando, Kathleen Soriano y Sofía Rodríguez Bernis el cómo, la creación femenina se veía infravalorada e invisibilizada, a pesar de la ley de igualdad, en las instituciones públicas. El Museo y Centro Nacional Reina Sofía y otros centros de referencia como el MACBA (con un 18\% de mujeres expuestas hasta el 2015) o las ferias de arte como ARCO (con un $6 \%$ de mujeres artistas españolas en esta última edición), repiten todas la misma mala praxis. (MAV: 2018).

Esto supone, como se mencionaba con anterioridad, una irreparable dinámica circular en la que las mujeres no son expuestas, porque no son visibles, y si no son visibles, se 
las premia menos, y si se las premia menos, valen menos, y si valen menos, se las reconoce menos y por lo tanto no se las expone ni se compran sus obras...

Este círculo vicioso se hereda de una generación a otra si no se produce un cambio que sustituya a una élite liderada por un patriarcado androcéntrico que poco mira, y que ignora la creación de las mujeres.

También es necesario preguntarse cuánto invierte el museo, no sólo en adquirir obras de mujeres artistas, dado que siempre es muy inferior al presupuesto destinado a la compra de obras de hombres, sino cuánto es el gasto que se dedica a todo el proceso expositivo como: pagar sus derechos de exhibición, honorarios, producción de la obra, catálogo, dispositivos de montaje, difusión, etc.

Si además añadimos los espacios que ocupa la mujer dentro de las escalas de visibilidad, comprobaremos que siempre ocupamos los lugares menores, los menos visibles como: almacenes y espacios secundarios, los de mínimo presupuesto.

Tan importante es el dato sobre número y nivel de las exposiciones individuales y colectivas en las que participan las mujeres artistas españolas, como su presencia inevitable en las exposiciones permanentes, formando parte de la colección, y no solo en los almacenes, sino conformando el relato fundamental del espacio museístico ante el público.

El relato que ofrecen los museos españoles es incompleto y lleno de lagunas, que en los casos de artistas ya muertas es imposible de remediar, y ello no se soluciona simplemente con organizar un itinerario feminista para acallar voces discordantes.

\section{Conclusiones}

El arte visual contemporáneo es un apasionante mundo donde la creación hace posible que las personas podamos expandir nuestro pensamiento, imaginar, fabular y reflexionar a través de ficciones, futuribles, o realidades. Esta increíble forma humana de expandirse fuera de los límites de nuestro cuerpo, tiempo y espacio, está siendo negado a una parte de la humanidad, y por ende, se está empobreciendo a la propia creación humana, mutilando el discurso feminista, que difiere, como se ha visto con anterioridad al androcéntrico, tanto en las formas de creación, como en la manera de gestión de las creaciones, así como, su puesta en escena y su venta.

Las formas de hacer feministas, no buscan imitar los modelos hegemónicos que refuerzan sus dispositivos invisibles de opresión, sino que se piensa en hacer, crear y reflexionar desde un lugar autónomo y diferente, A.I.R es un ejemplo sostenible, poderoso y bello para el movimiento feminista. Perseguir esas formas de hacer libre, en el arte visual, es 
una de las máximas de la asociación. Conquistando día a día micro gestos cotidianos que hacen que las leyes no se vacíen, y que las formas aparentes de ser feministas dejen paso a los verdaderos actos de igualdad, en donde la ley, por vulnerar un derecho, sea contundente con quien no la cumple; y en la cual los comités ejecutivos, se ocupen por puestos paritarios, o por mentes feministas, y que la sociedad, por fin, pueda ser más democrática, igualitaria y rica.

Una habitación propia, como reivindicaba Virginia Woolf ya en 1929, para poder expandir nuestra condición humana, creativa y natural, una habitación propia para poder construir las mimbres de una sociedad enriquecida por la diversidad de sus representaciones.

\section{Referencias bibliográficas}

Aguilar, Pilar (1998). «Mujer, amor y sexo en el cine español de los '90. Serie Cine», Madrid: Fundamentos.

Barrett, Michele (1993). «Prólogo a Woolf, Virginia, A room of One's Own», Londres: Penguin. BOURDIEU, Pierre (1977). «La reproducción. Elementos para una teoría del sistema de enseñanza», Barcelona: Laia.

DURÁN, María Ángeles (2012). «El trabajo no remunerado en la economía global», Madrid: Fundación BBVA.

EAGLETON, Mary (1986). «Feminist literary theory (A reader)», Massachusetts: Malden Laia.

FanNON, Frantz (2009) [1952]. «Piel negra, Máscaras Blancas», Madrid: Akal.

FREIXAS, Laura (2009). «La novela femenil y sus lectrices», Córdoba: Universidad y Diputación de Córdoba.

FouCAULt, Michel (1985). «Un diálogo sobre el poder y otras conversaciones», Madrid: Alianza. _ 1992). «Microfísica del poder», Madrid: La Piqueta.

Gramscl, Antonio (1998). «Escritos Políticos (1917-1933)», Madrid: Siglo XXI.

Hernando, Almudena (2015). «Mujeres, hombres y poder», Madrid: Traficantes de Sueños.

LACLAU, E. y MOUfFE, Ch. (2004). «Hegemonía y estrategia socialista: hacia una radicalización de la democracia», Buenos Aires: Fondo de Cultura Económica.

Ministerio de Cultura (2011). «Mujeres y Cultura. políticas de lgualdad» Madrid: Publicaciones AGE.

Woolf, Virginia. (1967). «Una habitación propia», Madrid: Seix Barral, Biblioteca Formentor. 


\subsection{Webgrafía}

Media Netwworks: Andy Warhol and the Guerrilla Girls, 2016 Disponible en: https://www. guerrillagirls.com/exhibitions/(Fecha de consulta: 1/5/18).

Women Art Revolution is a documentary film, created by Lynn Hershman Leeson, 2010 Disponible en: https://en.wikipedia.org/wiki/!Women_Art_Revolution (Fecha de consulta: 8/5/18).

A.I.R. Gallery: The History Show, Sept. 16 - Dec. 12, 2008 at Tracy/Barry Gallery, Bobst Library, NYU Disponible en: https://en.wikipedia.org/wiki/A.I.R._Gallery (Fecha de consulta: 8/5/18).

Bienal Mitrada de Mujeres Disponible en: http://www.bienalmiradasdemujeres.org/ (Fecha de consulta: 8/5/18).

Mujeres en las Artes Visuales Disponible en: .www.mav.org.es (Fecha de consulta: 8/5/18). Revista Arte y Cultura Visual Disponible en: http://www.m-arteyculturavisual.com/editorial/ (Fecha de consulta: 8/5/18). 